\title{
A population-based study of Sedentary Behavior, Coffee and Caffeine Intake, Education Level Associated with Obesity Risk among Young Adult
}

\author{
Esti Nurwanti ${ }^{1,2}$ and Chyi-Huey Bai ${ }^{1,3,4}$ \\ ${ }^{1}$ International Graduate Program in Medicine, College of Medicine, Taipei Medical University, Taiwan, ${ }^{2}$ Department \\ of Nutrition, Faculty of Health Science, Universitas Alma Ata, Yogyakarta, Indonesia, ${ }^{3}$ Department of Public Health, \\ College of Medicine, Taipei Medical University, Taiwan and ${ }^{4}$ School of Public Health, College of Public Health, \\ Taipei Medical University, Taiwan.
}

Low activity and high sitting was associated with increased obesity odds among young adults ${ }^{(1)}$. But, high coffee intake can reduce the risk of obesity ${ }^{(2)}$. College graduate and not college graduate have different sedentary behavior and coffee and caffeine intake. Presumably, education level can affect relationship between sedentary behavior, coffee and caffeine intake, and obesity. The aim of this study is to examine the association between sedentary behavior, coffee and caffeine intake, and obesity risk among college graduate and not college graduate in Indonesia.

This study using secondary data from Indonesian Basic Health Research survey which was collected in 2013. Then, 218,975 adults aged 18-35 years were selected. Education level was categorized into 2 groups: college graduate and not college graduate. They were measured body mass index and were interviewed to evaluate sedentary behavior and dietary intake using validated questionnaire with physical activity and food card. BMI was calculated as weight $(\mathrm{kg}) / \mathrm{height}\left(\mathrm{m}^{2}\right)$ and was determined based on WHO for Asian Population: normal weight $\left(18.5\right.$ to $\left.<23 \mathrm{~kg} / \mathrm{m}^{2}\right)$, overweight $\left(23.0\right.$ to $\left.<27.5 \mathrm{~kg} / \mathrm{m}^{2}\right)$ and obese $\left(\geqslant 27.5 \mathrm{~kg} / \mathrm{m}^{2}\right)^{(3)}$. Sedentary behavior were recorded as hours. Sedentary activity were coded as $(1)<3 \mathrm{~h},(2) 3-5 \mathrm{~h},(3) \geqslant 6 \mathrm{~h}$ based on other study ${ }^{(4)}$.

Among obese people, the percentage of not college graduate $(9.41 \%)$ were higher than college graduate $(1.28 \%)$. The percentage of moderate sedentary behavior $(4.36 \%)$ also higher than low sedentary $(3.92 \%)$ or high sedentary $(2.41 \%)$ behavior. Then, the percentage of low coffee $(8.36 \%)$ and caffeine $(10.10 \%)$ beverages intake also higher than high intake of coffee $(2.34 \%)$ and caffeine beverages $(0.59 \%)$. Pearson Chi-Square analysis was showed that sedentary behavior significantly associated with the presence of obesity among not college graduate $(\mathrm{p}<0.001)$, but college graduate were not significant $(\mathrm{P}=0 \cdot 2109)$. Coffee intake also have significantly associated with obesity both in college graduate and not college graduate $(p=0.0012$ and $p<0.0001)$. Similar significant association also found in Caffeine beverages (except coffee) with obesity both in college graduate and not college graduate $(p=0 \cdot 0057$ and $\mathrm{p}=0.0226)$.
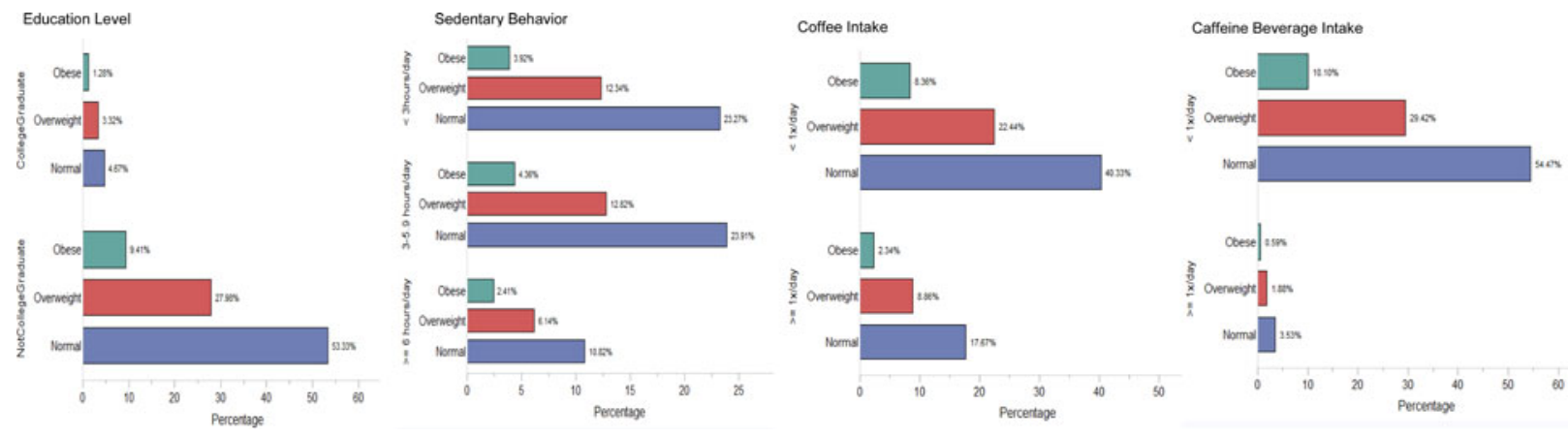

In conclusion, physical activity education to reduce sedentary behavior is particularly important, especially among those who have low education level. Moreover, coffee and caffeine consumption may be can reduce obesity risk among young adult.

1. Cleland V, Schmidt M, Salmon J, Dywer T \& Venn A (2014) Combined associations of sitting time and physical activity with obesity in young adults. $J$ Phys Act Health 11(1), 136-44.

2. Nordestgaard AT, Thomsen M \& Nordestgaard BG (2015) Coffee intake and risk of obesity, metabolic syndrome and type 2 diabetes: a Mendelian randomization study. Int J Epidemiol 44(2), 551-65.

3. WHO (2004) Appropriate body-mass index for Asian populations and its implications for policy and intervention strategies. The Lancet 363, 157-63.

4. Katzmarzyk PT \& Lee IM (2012) Sedentary behaviour and life expectancy in the USA: a cause-deleted life table analysis. BMJ Open 2(4). 